Weert, J.C.M. van, Jansen, J., Spreeuwenberg, P.M.M., Dulmen, S. van, Bensing, J.M. Effects of communication skills training and a Question Prompt Sheet to improve communication with older cancer 7 patients: a randomized controlled trial. Critical Reviews in Oncology Hematology: 2011, 80(1), 145-159

\begin{tabular}{|l|l|}
\hline Postprint Version & 1.0 \\
\hline Journal website & $\underline{\text { http://dx.doi.org/10.1016/j.critrevonc.2010.10.010 }}$ \\
\hline Pubmed link & $\underline{\text { http://www.ncbi.nlm.nih.gov/pubmed/21075644 }}$ \\
\hline DOI & $10.1016 /$ j.critrevonc.2010.10.010 \\
\hline
\end{tabular}

This is a NIVEL certified Post Print, more info at http://www.nivel.eu

\title{
Effects of communication skills training and a Question Prompt Sheet to improve communication with older cancer patients: A randomized controlled trial
}

JULiA C.M. VAN WEERT ${ }^{\mathrm{A}}$, JESSE JANSEN ${ }^{\mathrm{B}}$, PETER M.M. SPREEUWENBERG ${ }^{\mathrm{C}}$, SANDRA VAN DULMEN ${ }^{\mathrm{C}}$ AND JOZIEN M. BENSING ${ }^{\mathrm{C}, \mathrm{D}}$

${ }^{a}$ Amsterdam School of Communication Research ASCoR, Department of Communication Sciences, University of Amsterdam, Kloveniersburgwal 48, 1012 CX Amsterdam, The Netherlands

${ }^{\mathrm{b}}$ Screening and Diagnostic Test Evaluation Program, Centre for Medical Psychology and Evidence Based Decision Making, Sydney School of Public Health, University of Sydney, New South Wales, Australia

${ }^{c}$ Netherlands Institute for Health Services Research (NIVEL), P.O. Box 1568, 3500 BN Utrecht, The Netherlands

${ }^{\mathrm{d}}$ Faculty of Social and Behavioural Science, Utrecht University, The Netherlands

\begin{abstract}
A randomized pre- and post-test control group design was conducted in 12 oncology wards to investigate the effectiveness of an intervention, existing of a communication skills training with web-enabled video feedback and a Question Prompt Sheet (QPS), which aimed to improve patient education to older cancer patients ( $\geq 65$ years). The effects were studied by analyzing questionnaires and video recordings of patient education sessions preceding chemotherapy with 210 different patients.

Patients' recall of information was the primary outcome of the study. Recall was checked against the actual communication in the video-recordings. Moreover, communication skills were assessed by observing the extent to which nurses implemented 67 communication aspects, categorized in seven dimensions, using the QUOTE $^{\text {chemo }}$. Experimental nurses demonstrated a significant intervention effect on communicating realistic expectations. Within-group improvements were measured in the experimental group for tailored communication, affective communication and interpersonal communication. Although the use of a QPS significantly increased question asking, only limited results were found on older patients' recall scores. The overall proportion recall of recommendations showed a marginally significant pre-/post-change in proportion recall in favour of the experimental group and there was a significant pre-/post-change in two out of six sub-categories. The results indicate that nurses' communication skills can be improved by communication skills training. More research is needed to understand the difficult relationship between patient-provider communication and recall of information.
\end{abstract}

\section{INTRODUCTION}

\subsection{Older cancer patients' communication needs}

Effective communication surrounding treatment is known to be the key to optimal health outcomes. However, health care professionals frequently lack the communication skills needed to identify patients' individual concern and problems [1]. As a consequence, the information provided is often insufficiently tailored to the patients' needs (see Hack et al. [2], for a review). Although a large body of literature addresses cancer patients' information and communication needs, very little is known about the needs of older cancer patients ( $\geq 65$ years). In a recent literature review, no study could be identified that focused 
Weert, J.C.M. van, Jansen, J., Spreeuwenberg, P.M.M., Dulmen, S. van, Bensing, J.M. Effects of communication skills training and a Question Prompt Sheet to improve communication with older cancer 7 patients: a randomized controlled trial. Critical Reviews in Oncology Hematology: 2011, 80(1), 145-159

specifically on older cancer patients' needs [3]. The results from the studies that mentioned something about the presence or absence of age differences suggest that older patients in general seem to have less prominent needs for communication regarding the effect of cancer treatment on sexuality and body appearance and lower needs for psychosocial support than younger patients. Moreover, most older cancer patients want to receive relevant information about their treatment, but are relatively less interested in extensive and detailed information [3].

This might be explained by the fact that, compared with their younger counterparts, older people process information more slowly than younger ones [4], they perceive more difficulties in organizing and storing information [5] and experience a reduced capacity to ignore irrelevant information [6]. Moreover, remembering medical information and treatment recommendations may be more problematic for older patients as vision and hearing functions decrease which is known to predict change in memory performance [7]. On the other hand, there is a growing body of literature suggesting that older cancer patients are better able to regulate their emotions and cope with illness than younger ones, which might counteract the effects of cognitive decline on recall of information [8].

According to the Elaboration-Likelihood Model, personal relevant, that is tailored information, is processed more deeply (using the central routing instead of the peripheral routing) and is therefore likely to improve comprehension and recall of information, i.e. remembering and reproduction [9], [10], [11], [12], [13], [14] and [15]. This might, ultimately, contribute positively to treatment compliance, patient satisfaction, health and well-being [16]. Recall in older cancer patients is expected to benefit even more from tailored information as older people prefer to invest their cognitive resources in goal-relevant activities [8] and [17]. Information is also processed more deeply when the message quality, i.e. the content of the information, is high [10], [12] and [13]. This means that, to improve recall, the information should not only be tailored to meet patients' needs, the information itself should be of sufficient quality too.

Communication between health care providers and older cancer patients is not only complicated by agerelated problems, such as cognitive decline [18] and sensory impairments [7], but also by a variety of other factors, such as patients' beliefs, perceptions and knowledge about cancer [19]. As oncology patients in general continuously seem to have unmet needs [2] and unfulfilled information needs influence quality of life more negatively in older compared to younger patients [20], understanding older cancer patients' information needs and adapting the communication to those needs is essential [16]. Hardly any research has been conducted in this area.

\subsection{Background of the study}

The current study is part of a larger study that aimed (1) to examine what specific needs have to be addressed in health education preceding chemotherapy treatment (CT) in older cancer patients; (2) to develop recommendations to tailor the communication process to older patients' needs and to implement an intervention based on these recommendations and (3) to evaluate the effectiveness of this intervention. The Medical Research Council's evaluation framework (MRC framework) [21] and [22] was used to adopt appropriate methods. According to this framework, a key early task in the development of a complex intervention is to develop a theoretical understanding of the likely process of change by drawing on existing evidence and theory, supplemented if necessary by new primary research [22]. Especially the early stages of RCT development are essential to make a RCT run properly. We therefore started the study with extensive research on the state-of-the-art and current practice, including a systematic review on older cancer patients' needs [3], focus group interviews with older cancer patients and their partners as well as experts in the field of communication, gerontology, oncology and/or nursing [23] and video recordings of nursing consultations with older cancer patients preceding CT extended with questionnaires on recall of information and patients' needs [24], [25] and [26].

\subsection{Room for improvement}

Oncology nurses play an important role in patient education about chemotherapy treatment (CT) by providing information about the treatment and (handling) potential side effects. Our analyses of videotapes of these educational consultations with older cancer patients in the first phases of the overarching study showed that patients were overloaded with information and had poor active reproduction: only $23.6 \%$ of the recommendations given by the nurse could be recalled [24]. Moreover, the information provided was often general and insufficiently tailored to individual needs and circumstances of both patients and family members [23], [25] and [27]. Patients also reported unfulfilled needs in talking about the future, i.e. realistic 
Weert, J.C.M. van, Jansen, J., Spreeuwenberg, P.M.M., Dulmen, S. van, Bensing, J.M. Effects of communication skills training and a Question Prompt Sheet to improve communication with older cancer 7 patients: a randomized controlled trial. Critical Reviews in Oncology Hematology: 2011, 80(1), 145-159 ive

expectations about treatment outcomes and prognosis [25]. The results of this previous work provided a good basis for developing an intervention to improve oncology nurse communication with older cancer patients preceding CT, following the MRC framework [21] and [22]. The intervention consisted of a communication skills training for nurses preceded by web-enabled video-feedback on a real-life consultation, accompanied by a booklet with a Question Prompt Sheet (QPS) for patients, i.e. a structured list of questions designed to encourage patients to ask questions (see Section 2.4.4). The purpose of the current study was to evaluate the effects of the intervention on communication skills of nurses as well as older cancer patients' recall of information. In particular, it was hypothesized that the intervention would lead to measurable changes in:

- Oncology nurses' communication skills: more tailored communication, interpersonal communication, affective communication and talking about the future, i.e. discussing realistic expectations.

- Content of the information provided: setting priorities in the provision of treatment related topics as measured by decreased information overload. This means that the amount of treatment-related information and rehabilitation information was expected to decrease.

- Older cancer patients' recall of information: improved recall (proportion remembered).

\section{METHODS}

\subsection{Design}

A randomized pre- and post-test design was used. The study was performed in 12 wards of 10 Dutch hospitals. Randomization took place at ward level to prevent contamination of the control group, which was considered a potential threat to the study's internal validity [22]. After the pre-test, the wards were randomized by having lots drawn from a sealed container by an independent person. The nurses from the experimental wards received the intervention, consisting of individual web-enabled video-feedback, a oneday communication skills training, a follow-up meeting and the implementation of a booklet with a QPS. The intervention (see Section 2.4) was based on the results of the pre-test [3], [23], [24] and [25]. The control wards continued to provide patient education as usual and received the intervention after the posttest. The participating hospitals signed an agreement in which they promised that, in case of being randomized as control group, they would refrain from communication training during the study period. Measurements were performed at baseline (pre-test) and directly after the implementation period (post-test). The data-collection and intervention period between the pre- and post-test lasted from February 2005 to June 2008 and participating wards were consecutively included. The implementation of the intervention lasted three months per ward, starting between September 2006 (ward 1) and April 2007 (ward 6). The Medical Ethical Committee of the University Medical Centre Utrecht, the Netherlands, granted permission for the study supplemented by local feasibility statements from all participating hospitals. Fig. 1 gives a summary of the design of the study.

\section{[FIGURE. 1]}

\subsection{Subjects}

To be eligible for the study, patients had to meet the following inclusion criteria: (1) aged 65 years or older; (2) receiving chemotherapy for the first time or for the first time in 5 years; (3) not participating in a Phase III clinical trial; (4) sufficient command of the Dutch language; and (5) no non-age related cognitive impairment (according to the medical file).

Eligible nurses had to meet the following criteria: (1) certified to provide oncology care and (2) providing patient education about chemotherapy as part of their regular employment duties. Temporary staff and students were not eligible. During the pre-test, we tried to include as many different nurses as possible. During the post-test, we aimed at including all nurses who participated in the pre-test. Following the intention-to-treat principle, we also wanted to include each patient who gave informed consent. Due to the nurses' duty schemes it was not always possible to videotape the preferred nurse. In the experimental group, 43 nurses were included: 20 in both pre-test and post-test, 12 in pre-test only and 11 in post-test only. In the control group, 34 nurses participated: 15 in pre-test and post-test, 11 in pre-test only and 8 in post-test only (see Section 2.6 for statistical handling). The nurses participated in the study and training 
Weert, J.C.M. van, Jansen, J., Spreeuwenberg, P.M.M., Dulmen, S. van, Bensing, J.M. Effects of communication skills training and a Question Prompt Sheet to improve communication with older cancer 7 patients: a randomized controlled trial. Critical Reviews in Oncology Hematology: 2011, 80(1), 145-159

program as part of their regular employment duties. Two of the 79 nurses $(2.5 \%)$ refused to participate in the data collection.

\subsection{Procedure}

Before the consultation, written informed consent to videotape the consultation was given by patients and nurses. The consultation was videotaped using an unmanned video-camera. Immediately after the consultation, patients completed a questionnaire, including background characteristics and a recall measurement. A researcher was available to read the questions aloud, if necessary. After the consultation, nurses were asked how they had experienced being videotaped. Although most of them reported to have experienced some anticipatory tension, the stress generally disappeared once the consultation had started. Thus, the majority of nurses reported that the consultation reflected the normal situation.

\subsection{Intervention}

The intervention was developed in collaboration with the Netherlands Cancer Institute (NCI) and based on the findings of the pre-test. The intervention consisted of (1) web-enabled video feedback, (2) a one-day training session, (3) a follow-up meeting, and (4) a patient booklet including a Question Prompt Sheet (QPS).

\subsubsection{Web-enabled video feedback}

Prior to the training, experimental nurses received a safe 'personal web link' to one of their recorded consultations collected during the pre-test, which enabled them to watch the consultation at the hospital or at home. Nurses were instructed to watch this video-taped consultation and to complete a reflection task, that was developed for this study. The outcomes of the reflection task were discussed during an one-hour, individual feedback session at the hospital, at the end of which individual training goals were formulated.

\subsubsection{Communication training}

Following the feedback session, all nurses were sent a complete reader by post [25] and [28]. This reader contained a theoretical framework on communication with older cancer patients as well as a summary of the results from pre-test and practical exercises. Theories that were used are, next to literature on communication with older people, the stress-coping theory of Lazarus and Folkman [29] and [30], the selfregulation theory [31] and [32] and Millers' theory on coping with illness by monitoring or blunting of threatening information [33].

The training aimed at enhancing nurses' knowledge and skills regarding patient education about CT for older cancer patients and structuring the educational sessions differently (see Fig. 2). The main findings of the pre-test resulted in the following specific training goals for nurses:

- set priorities after an adequate preparation of the consultation, i.e. being less extensive in giving all possible treatment-related information and rehabilitation information, but focus on the most important information for this specific patient;

- tailor information to older patients' individual situation and needs;

- address patients' emotions;

- discuss realistic expectations, e.g. regarding prognosis, in an appropriate way;

- use a QPS;

- structure the information presented and implement a short break to allow the patient and significant others to reflect on the information given.

\section{[FIGURE. 2.]}

As tailored information is supposed to be time-efficient, we explicitly aimed not to increase the length of the consultation (scheduled $1 \mathrm{~h}$ ).

The in-house training session took up a whole day in which a combination of learning methods was used, including role play. The nurses were trained by an experienced and qualified professional trainer from the NCI. We aimed to train complete teams, i.e. all nurses from participating wards who provide patient education about CT (regardless of whether they were videotaped or not). In total, 48 oncology nurses from the six experimental wards attended five in-house training sessions (6-11 nurses per group). Two wards 
Weert, J.C.M. van, Jansen, J., Spreeuwenberg, P.M.M., Dulmen, S. van, Bensing, J.M. Effects of communication skills training and a Question Prompt Sheet to improve communication with older cancer 7 patients: a randomized controlled trial. Critical Reviews in Oncology Hematology: 2011, 80(1), 145-159

were trained together, because of the limited number of oncology nurses providing patient education about chemotherapy in these wards.

\subsubsection{Follow-up meeting}

Six weeks after the training day, a half-day follow-up meeting was conducted by the same trainer (for each ward separately). In preparation for this meeting, nurses sat in on each other's consultations and practised in giving each other feedback, using the reflection task that was also completed for the video feedback. The first aim of the follow-up meeting was to refresh and deepen the communication skills. The second aim was to support the implementation at an organizational level (e.g. providing nurses with a consultation room, access to patient records) and discuss the logistics behind the distribution of the QPS. For this purpose, the manager of the team also attended this meeting. A researcher was present to take notes of the discussion and agreements that were reached. One of the issues that emerged from the follow-up sessions was the lack of consensus within hospitals/wards regarding the information about treatment and side effects that need to be discussed in the consultation. All experimental wards decided during the follow-up meeting to arrange team meetings to discuss the relative importance of different information for the different treatment regiments, based on the most common side effects and complications for each treatment regimen. This was considered helpful to set priorities for information to be discussed during the patient education session. Another issue was the preparation of the consultation. Nurses' had often no access to the medical file and were thus provided with very little background information about the patients' history and treatment. As a result, history taking took quite a lot of time during the consultation. It was discussed how a better preparation, including insight in the patients' medical history preceding the consultation, could be reached in each ward.

\subsubsection{Question Prompt Sheet}

In conjunction with the reader we developed a patient booklet including a QPS for patients. A QPS is a structured list of questions designed to encourage patients to acquire information that is personally relevant for them during a health care encounter and is supposed to enhance tailored communication [34]. The QPS developed in this study contained 17 different topics, ranging from treatment-related topics and dealing with side effects to emotional topics, coping with illness and sexuality. Patients received the booklet with QPS before the educational consultation about CT and could mark which topics they would like to discuss.

One year after the training, the research team attended a team meeting, in which implementation progress was discussed. The teams reported that they indeed succeeded in consensus about the most important treatment-related information that has to be given during the first consultation, particularly regarding side effects.

All information about this study (VOICE) and the intervention can been downloaded from the special website www.nivel.nl/voice.

\subsection{Measurements}

The primary outcome measure was 'recall of information' (see Section 2.5.3). As the instrument to measure recall of information was especially developed for this study (in the pre-test), a power-analysis at forehand was not possible. Based on previous studies that used similar methodologies, we estimated that we needed 50 participants in each arm in pre- and post-test.

\subsubsection{Background characteristics}

The self-administrated questionnaire contained socio-demographic items inquiring about age, gender, education and living situation. Additional medical background characteristics (diagnosis, time since diagnosis and treatment goal) were obtained from the medical file.

Frailty was measured using the Groningen Frailty Indicator (GFI), a 15-item screening instrument to determine a person's level of frailty [35]. The GFI screens for the loss of functions and resources in 4 domains of functioning: physical (mobility functions, multiple health problems, physical fatigue, vision, hearing), cognitive (cognitive functioning), social (emotional isolation), and psychological (depressed mood and feelings of anxiety), and was found to be a one-dimensional concept with good reliability and validity [36]. A total score was counted (range 0-15), with higher scores indicating more frailty. 
Weert, J.C.M. van, Jansen, J., Spreeuwenberg, P.M.M., Dulmen, S. van, Bensing, J.M. Effects of communication skills training and a Question Prompt Sheet to improve communication with older cancer 7 patients: a randomized controlled trial. Critical Reviews in Oncology Hematology: 2011, 80(1), 145-159 1 Ve

Current levels of generalized anxiety were measured with the shortened, Dutch version of the State-Trait Anxiety Inventory (STAI), a widely used scale that demonstrated good reliability and validity [37], [38] and [39]. Respondents indicated their level of anxiety on a 4-point Likert scale on each of the 10 items. A total score was calculated (range 10-40) with higher values representing higher levels of anxiety. Cronbach's Alpha for the scale was 0.91 in this sample.

\subsubsection{Quality of communication}

The quality of communication was measured by the QUOTE ${ }^{\text {chemo }}$-Performance. As there were no validated questionnaires available that were appropriate for the study goals, the QUOTE ${ }^{\text {chemo }}$ was developed for this study [26], following the widely used QUOTE (Quality Of care Through the patients' Eyes) methodology [40], [41] and [42]. The QUOTE ${ }^{\text {chemo }}$ consists of two parts, i.e. the QUOTE ${ }^{\text {chemo }}$-Importance and the QUOTE ${ }^{\text {chemo }}$-Performance. They each contain the same 67 items. The QUOTE ${ }^{\text {chemo }}$-Importance was completed by patients and used in the pre-test to get insight in older cancer patients communication needs surrounding CT. The QUOTE ${ }^{\text {chemo }}$-Performance was used in the current study to get insight in the effectiveness of the intervention on nurses' communicative behaviour by an independent assessment of the quality of nurses' communication. The extent to which the nurses implemented the 67 communication aspects during the consultation was rated by trained observers on a 4-point Likert scale (1) 'not at all'; (2) 'a little'; (3) 'moderately'; (4) 'maximally'. The 67 items of the QUOTE ${ }^{\text {chemo }}$ were categorized in seven dimensions according to the typology developed by Rutten et al. [43]. We distinguished three cancerrelated categories: (1) treatment-related information; (2) realistic expectations; (3) rehabilitation information; and four generic communication skills categories: (1) tailored communication; (2) affective communication; (3) coping information; and (4) interpersonal communication. The category coping information concerned topics such as information about community counseling or support from other patients. We know from the literature and from our pre-test results that at the beginning of treatment patients consider these topics relatively less important [25] and [43]. Therefore, we did not expect changes in this category.

The development and psychometric properties of the QUOTE $^{\text {chemo }}$ are extensively described elsewhere [26]. This validation study was conducted in a different sample and showed that the QUOTE ${ }^{\text {chemo }}$ captured relevant issues of concern with good internal consistency, satisfactory item-total correlations and convergent validity. Factor analysis using structural equation modelling (SEM) confirmed the factor structure of the seven communication QUOTE ${ }^{\text {chemo }}$ dimensions.

In the current study, five independent observers rated the video-observations of the nursing encounters preceding chemotherapy. They were blind for whether the nurse was included in the experimental or the control group. Observation scores on the seven QUOTE ${ }^{\text {chemo }}$ categories were rated as the mean of the scores on the relevant items (range of the subscales 1-4). Interrater reliability (mean Cohen's Kappa) was 0.49, which can be considered as moderate [44]. Table 1 gives an overview of the categories, their content and the Cronbach's alpha's in the present study.

\section{[TABLE 1.]}

\subsubsection{Content analysis and recall of information}

Recall was measured using the 'Netherlands Patient Information Recall Questionnaire (NPIRQ)', that was completed immediately after the consultation. The questionnaire was developed in conjunction with an extensive observation checklist that was used to make a detailed content analysis of the information provided [24]. Items recalled in response to 11 open-ended questions about treatment recommendations were compared with items mentioned by the nurse during the videotaped consultation. The percentages (proportional) of facts recalled accurately were calculated. If the topic had not been discussed in more than one third of the consultations, recall was not rated. The video-observations were conducted by blinded observers. Interrater reliability (mean Cohen's Kappa) was good with 0.79 for the content analysis of the videos and 0.96 for coding responses to the recall questions [24] and [44]. The development of the instrument has been described in detail elsewhere [24].

\subsubsection{Amount of questions}


Weert, J.C.M. van, Jansen, J., Spreeuwenberg, P.M.M., Dulmen, S. van, Bensing, J.M. Effects of communication skills training and a Question Prompt Sheet to improve communication with older cancer 7 patients: a randomized controlled trial. Critical Reviews in Oncology Hematology: 2011, 80(1), 145-159

In the post-test video recordings, the number and kind of questions asked by the patient and companions about topics mentioned in the QPS were counted by the observer.

\subsection{Data analysis}

Descriptive statistics were obtained on the demographic characteristics of subjects. Differences between groups (experimental and control; pre-test and post-test) in age, gender, education, diagnosis, time since diagnosis, GFI and STAI were examined by using $t$-test and $\chi^{2}$ test, where appropriate.

As not all participating nurses could be included in both pre- and post-test, multilevel analysis, carried out with MlwiN-software, was used for analyzing the data [45]. A mixed model of multilevel analysis for repeated measurements was chosen, which takes into account all available data: the paired samples of nurses who participated in pre- and post-test as well as the unpaired data of nurses who only participated in pre-test or post-test [46] and [47]. The multilevel analysis also accommodated for dependencies among measurement, caused by the hierarchical structure of the data (measurement occasions nested within nurses, who are nested within wards). Three levels of analysis were distinguished: (1) measurement (pre- or posttest), (2) nurse and (3) ward. The correlated measurements of nurses who participated in both pre- and posttest are controlled for by modelling the covariance between the pre- and post-measurement at the nurse level. By including the ward level, the 'nurse nested within ward' effect is accounted for.

Change scores were computed to compare the rate of change across the experimental and the control group on each measure from pre- to post-test. The mean pre-test post-test differences in the experimental group were tested against the mean pre-test post-test differences in the control group. Additional adjusted analysis were conducted on all outcomes in which the following characteristics were added as covariates because earlier studies showed a relationship with outcomes, particularly with recall of information: patients' age [48], [49] and [50], gender [51] and [52] and education [8], [27] and [53].

\section{RESULTS}

\subsection{Response}

In total, 361 patients were informed about the study and asked to give written consent. Eighteen patients did not meet the inclusion criteria and had to be excluded afterwards, leaving 343 eligible patients. Of these, 115 patients $(33.5 \%)$ refused to participate. They felt it was too much $(n=69)$, were too tired or too ill $(n=10)$, did not want to be videotaped $(n=16)$ or had other reasons for non-response $(n=20)$. Eighteen patients $(5.2 \%)$ could not be included due to logistical reasons (e.g. ward forgot to enter the patients' name to the researchers, time schedule changed, traffic delay). In total, 210 older cancer patients $(61.2 \%)$ participated in the study: 115 in the pre-test (64 in the experimental group and 51 in the control group) and 95 in the post-test (55 in the experimental group and 40 in the control group). A non-response analysis revealed that non-participating patients were older $(M=73.7, \mathrm{SD}=6.8)$ than participating patients $(M=72.2, \mathrm{SD}=4.8 ; p<.05)$. There were no differences in gender between responding and non-responding participants. Of the resulting patients, $161(76.7 \%)$ completed the recall questionnaire.

\subsection{Background characteristics patients}

The majority of respondents was male $(65.2 \%)$ and lived with a partner $(65.2 \%)$. The mean age was 72.2 years $(\mathrm{SD}=4.8)$ and almost half of the respondent had a low education $(47.1 \%)$. The mean frailty score was $2.4(\mathrm{SD}=1.9)$. Considering patients with a frailty score of 4 or higher as moderately frail [36], we can conclude that the majority of included patients was not frail. Table 2 summarizes the socio-demographic and disease characteristics for subjects in the pre-test and the post-test. The table shows that the experimental and the control groups were to a large extent comparable. There was a significant difference in age between the experimental group and the control group at pre-test. There were no other differences between the experimental and the control group at pre-test and at post-test, nor between measures within the experimental group (pre-test versus post-test) and the control group (pre-test versus post-test), indicating that the randomization was successful. 
Weert, J.C.M. van, Jansen, J., Spreeuwenberg, P.M.M., Dulmen, S. van, Bensing, J.M. Effects of communication skills training and a Question Prompt Sheet to improve communication with older cancer 7 patients: a randomized controlled trial. Critical Reviews in Oncology Hematology: 2011, 80(1), 145-159

\section{[TABLE 2.]}

\subsection{Background characteristics nurses}

Table 3 shows the demographic characteristics of the participating nurses in the experimental group and the control group at baseline. There were no significant differences, and in both groups the majority of the nurses were female with an average age of 41 years.

\section{[TABLE 3.]}

\subsection{Consultation characteristics}

The average duration of the videotaped encounter was $55.3 \mathrm{~min}(\mathrm{SD}=15.7)$. There were no significant differences between the experimental and the control group in pre-test and post-test regarding consultation duration (see Table 4). This means that implementing a short break in the experimental group did not make the consultation longer.

\section{[TABLE 4.]}

During the pre-test, 115 video-recordings were made of 58 nurses $(M=2.0$ per nurse, range $1-7) ; 32$ nurses with 64 video-recordings in the experimental group and 26 nurses with 51 video-recordings in the control group. During the post-test, 95 video-recordings were collected of 54 nurses $(M=1.8$ per nurse, range 1-6); 31 nurses with 55 video-recordings in the experimental group and 23 nurses with 40 videorecordings in the control group.

\subsection{Outcomes}

\subsubsection{Effects on quality of communication}

The effects of the training on nurse's communication skills are presented in Table 4. The experimental group showed a significant, positive intervention effect in the category discussing realistic expectations. Within this category, there was especially improvement on the single items 'discussing expected survival' and 'discussing the future'. In the categories tailored communication, affective communication and interpersonal communication a significant within-group effect was found. The total pre-/post-change analysis did not reach significance, as the control group also slightly improved. Within the category tailored communication, significant improvement was found for the single items 'asking how much information the patient would like to know', 'checking the patients' expectations' and 'checking whether the patient still wants to start CT after being educated'. Items from the category affective communication that showed a significant, positive change are 'being attentive to how the patient is doing', 'lending a listening ear' and 'providing space for feelings and emotions'.

A significant decrease was found for the category rehabilitation information. This means that nurses in the experimental group were providing less rehabilitation information at post-test as compared with pre-test and the control group. Specific topics that decreased were 'discussing all possible side effects' and 'sexuality'. There were no significant changes in the categories treatment-related information and coping information.

\subsubsection{Effects on content of the consultation}

Extensive observations of the videotaped consultation gave a more in-depth insight in which specific items were discussed less during the consultation in the experimental group at post-test. Conform the aim of the training, the experimental group showed a significant decrease in the number of items discussed (see Table 5). We distinguished 'Information items' and 'Recommendations'. Within the 'Information items', less history taking was observed as well as less talking about all different side effects. As explained in the Section 2.4.2, these were both important points of attention during the training. On average, less items were discussed about side effects of the digestive system, skin, hair, eyes and ears. General well-being also showed an significant pre-/post-change, but this was caused by an increase in the control group instead of a decrease in the experimental group. Within 'Recommendations', there was a decrease in the amount of topics discussed concerning stools, mouth, skin and hair and side effects that have to be reported to the hospital staff. 
Weert, J.C.M. van, Jansen, J., Spreeuwenberg, P.M.M., Dulmen, S. van, Bensing, J.M. Effects of
communication skills training and a Question Prompt Sheet to improve communication with older cancer 7 patients: a randomized controlled trial. Critical Reviews in Oncology Hematology: 2011, 80(1), 145-159

\section{[TABLE 5.]}

During the post-test, significantly more questions were asked by patients and companions in the experimental group about treatment-related topics covered in the QPS $(M=17.82, S D=13.81)$ as compared to the control group $(M=12.28, S D=10.88 ; p<.05)$. In particular, patients in the experimental group asked more questions $(M=10.76, S D=10.22)$ than patients in the control group $(M=6.69$, $S D=7.90 ; p<.05)$. The majority of the questions concerned hospital routines, details of therapy and side effects (not in table).

\subsubsection{Effects on recall of information}

Table 6 shows that a limited intervention effect could be established on recall of information. The overall proportion recall of recommendations showed a marginally significant change in the post-test as compared to the pre-test in favour of the experimental group. There was a significant pre-/post-change in proportion recall of two specific categories of recommendations, namely recommendations on 'hygiene' and 'side effects that have to be reported to the hospital'.

\section{[TABLE 6.]}

The average number of recommendations (absolute) recalled was on average $6.98(\mathrm{SD}=4.03)$, i.e. 7.17 $(\mathrm{SD}=3.75)$ at pre-test $(7.3$ in the experimental group and 6.9 in the control group) and $6.77(\mathrm{SD}=4.36)$ at post-test (6.0 in the experimental group and 8.1 in the control group) (n.s.).

\section{DISCUSSION}

In this study, we used the rating of real communication on the QUOTE ${ }^{\text {chemo }}$-Performance to investigate the effects of a communication skills training on the actual communication skills of oncology nurses, who provide older cancer patients with information and support preceding chemotherapy treatment. The results showed a significant, positive intervention effect for discussing realistic expectations and within group effects in the experimental group for providing tailored communication, affective communication and interpersonal communication. This indicates that the training resulted in positive changes in the application of essential communication skills. As the control group slightly improved as well, the pre-/post-change of the experimental group did not significantly differ from the pre-/post-change in the control group with respect to tailored communication, affective communication and interpersonal communication. This might be explained by the concept of contamination. To reduce the contamination risk, we randomized at ward level and participating hospitals signed a cooperative agreement in which they promised that the control wards would not apply elements of the intervention during the study period. Moreover, participating nurses were asked not to talk with colleagues from other hospitals about the intervention. However, the experimental nurses were very enthusiastic about the intervention and oncology nurses are a very wellorganized, professional group with quite a lot of formal and informal meetings. Discussing the intervention during these meetings can therefore not be fully excluded. A follow-up meeting after the post-test to reflect on the findings with a panel of 10 participants (five from the experimental and five from the control group) indeed revealed that the control group had been slightly informed about the intervention.

The control group scores on discussing realistic expectations did not increase, but slightly decreased. It is known from literature that health care professionals in general seem to experience difficulties in discussing prognosis with cancer patients, especially when it concerns bad news [54] and [55]. It might be possible that a practical training in communication skills is especially important when it comes to discussing topics that have to do with prognosis and the future, which might explain why a contamination effect was not found in this category. Recently, guidelines have been prepared to assist clinicians with the difficult but important task to communicate prognosis information both sensitively and effectively [56]. It is recommended to combine these guidelines with a communication training.

The analysis also revealed that providing rehabilitation information decreased. A more extensive content analysis showed that the number of items discussed during the consultation significantly decreased. This was an intended result because it was convincingly found in the beginning of the study (pre-test) that patients were overloaded with information [24] and [25]. A prerequisite for balanced information giving is that nurses set the right priorities, which was one of the aims of the training. With the observation protocols we used in this study we only have limited information about whether or not nurses set the right priorities. 
Weert, J.C.M. van, Jansen, J., Spreeuwenberg, P.M.M., Dulmen, S. van, Bensing, J.M. Effects of communication skills training and a Question Prompt Sheet to improve communication with older cancer 7 patients: a randomized controlled trial. Critical Reviews in Oncology Hematology: 2011, 80(1), 145-159

However, setting the right priorities received continued attentions during team meetings in the experimental hospitals, as reported in the follow-up meetings. Furthermore, when we presented our findings to the above mentioned panel of 10 oncology nurses, they confirmed that, in their wards, fewer topics were discussed but these topics were discussed more extensively and better tailored to the individual needs and situations of patients. As we aimed to enhance the provision of personally relevant, high quality information, we feel that the results of the content analysis can be interpreted as positive intervention effects, provided that nurses indeed made the right choices in the issues they raised.

The number of questions patients asked about treatment related topics according to the QPS significantly increased in the experimental group. This was expected to facilitate the probability of receiving personal relevant information. Based on theoretical assumptions, increased provision of personal relevant information was expected to result in better recall of information [9], [10], [11], [12], [13], [14] and [15]. However, recall-scores only slightly improved. There was a marginally significant improvement in the total proportion of recommendations recalled. Moreover, a significant intervention effect was found for proportion recall of recommendations on 'hygiene' and 'which side effects have to be reported to the hospital'. As content analysis revealed that less topics were discussed on the latter, this indicates that setting priorities resulted in better recall scores. However, there were no other intervention effects on recall of information. There are three possible explanations for the limited improvement of the recall scores.

First, the pre-test resulted in the recommendation to provide more personal relevant information, but also to discuss realistic expectations in an appropriate way and to address patients' emotions. Nurses were therefore trained in adequately discussing these topics, guarded by the patient's request. However, recent research showed that the more prognostic information is discussed, the less patients can recall of the consultation [49]. The increased discussing of realistic expectations, including prognostic issues, in the experimental group might therefore have failed to increase the patients' recall of information. The same might apply to the discussion of distress or other emotional topics. Overviews of the psychological literature show that the relationship between emotions and memory is complex and context dependent [57], [58], [59] and [60]. It is possible that the patients' ability to concentrate on other information after having discussed stressful topics is diminished by 'attentional narrowing' [50], [57] and [61]: the discussion of stressful topics can become the centre of the patients' attention at the cost of other, more peripheral information, e.g. treatment-related information, that is not been processed and stored in memory and can therefore not be recalled [62]. This raises the questions whether a better recall of information indeed will result in higher needs fulfillment or patient satisfaction, as is supposed by Ley [63]. Future research has to give more insight in the complex relationship between recall of information and other patient outcomes.

A second explanation for the limited results on recall scores at post-test might be found in Millers' work [64], who states that the span of absolute judgment and the span of immediate memory impose severe limitations on the amount of information that we are able to receive, process, and remember. He argues that for a lot of different kinds of test materials a finite span of immediate memory is about seven items in length and found that there is a span of absolute judgment that can distinguish about seven categories and that there is a span of attention that will encompass about six objects at a glance [64]. In our study, the average number of recalled items is exactly seven (6.98) and in another recent study on recall of information, provided during consultations with oncologists, the number of items recalled ranged from 5.7 for patients aged 65 or older to 6.5 for younger patients [49]. Although these results must be interpreted with caution, a limitation in the amount of information that older cancer patients can recall might be an explanation for the limited intervention effects on recall of information.

The final explanation is a methodological one. We choose to measure recall of Recommendations as we considered the understanding and active remembering of recommendations crucial to be able to deal with treatment and side effects at home. However, the intervention that was developed -based on the pre-testfocused more on the decrease of the number of informational items than on the decrease of recommendations. Content analysis showed that the number of recommendations was not reduced in all categories for which recall was measured. This means that, at least in these categories, the chance to find significant intervention effects is diminished, although it must be noted that an intervention effect also could have been established if the number of items did not decrease, but the quality of the communication improved.

This brings us to another limitation of this study. The intervention was based on the results of the pre-test. To investigate the effectiveness of the intervention, we had to use the same measurement instruments 
Weert, J.C.M. van, Jansen, J., Spreeuwenberg, P.M.M., Dulmen, S. van, Bensing, J.M. Effects of communication skills training and a Question Prompt Sheet to improve communication with older cancer 7 patients: a randomized controlled trial. Critical Reviews in Oncology Hematology: 2011, 80(1), 145-159

during the post-test as during the pre-test. Although these measurements appeared to fit the testing of our hypothesis to a reasonable extent, some adaptations might have improved the design if we had known the content of the intervention beforehand. This might, for instance, have resulted in a higher chance to find effects on recall. On the other hand, it worked out very well to develop the intervention based on the findings of the pre-test. This appeared to be one of the reasons for the high motivation of participating nurses to implement what they had learned in practice and this also explains the absence of resistance among nurses to change their habits and to be willing to improve patient education. This argument is also strengthened in The Medical Research Council's evaluation framework (MRC framework) [21] and [22] that was used to develop the intervention. It is recommended to repeat the intervention in another sample of nurses, after a power analysis that can be based on the results of the current study and with shorter time between pre- and post-test.

A last limitation concerns the randomization procedure. We used cluster randomization (groups are randomly allocated to the experimental or control condition) as a solution to the problem of contamination of the control group. This design is one of the experimental designs for evaluating complex interventions [22] and seemed most appropriate for the study purposes. To take care of systematic differences between wards, we incorporated the ward level in the multilevel analysis. We also accounted in our analysis for the fact that not all participating nurses could be included in both pre- and posttest.

This study points to practical implications that can also be relevant for physicians working with this group. In an earlier study, it was found that more than half of the information provided by oncologists was forgotten [49]. Recommendations for practice include structuring the consultation (Fig. 2), giving information that is specifically adapted for individual patients rather than giving general information, encouraging patients to ask questions, for instance by using a Question Prompt Sheet, and prioritizing the most important, personally relevant information, e.g. those side-effects that can be prevented by the patient. Other recall promoting behaviours to enhance recall of information are organizing categorizing, repeating and summarizing information, detecting possible sensory deficits, minimizing distractions, encouraging patients to take notes and giving information at different time points [8]. It is especially recommended to be aware of repeating treatment-related information and advices during a follow-up consultation when the current consultation contains emotional elements.

To conclude, the findings of this study are encouraging for health care providers in oncology that communication skills can be improved by communication skills training. One of the assets of the training program is that it was built on a detailed analysis of current practice in the target group. This resulted in a training program that was tailored to the patients' as well as the nurses' needs. This seems to be a key factor in developing a successful training program [21] and [22]. Additional research is needed to unravel the difficult dynamics between patient-provider communication and patient outcomes, such as recall of information.

\section{CONFLICT OF INTEREST STATEMENT}

None declared.

\section{REVIEWERS}

Hilde Eide, Ph.D., Associate Professor, Nursing Department, Oslo University College, Oslo, Norway. Katrine J. Lavelle, Ph.D., The University of Manchester, The School of Nursing, Midwifery and Social Work, Jean McFarlane Building, University Place, Oxford Road, Manchester M13 9PL, United Kingdom.

\section{ACKNOWLEDGEMENTS}

We thank all the participants who were willing to participate in our study and completed extensive questionnaires during a very difficult period of their life. We are also grateful to the nurses who gave permission to videotape their consultations, actively participated in the communication skills training and implemented the intervention in their wards. We very much appreciate the support of the coordinators of the wards for their overall efforts in approaching eligible patients and implementing the intervention. In addition, we would like to thank Anneke de Best, professional trainer of the NCI, for her great support in the development of the intervention and the excellent way she trained the nurses. Furthermore, we thank 
Weert, J.C.M. van, Jansen, J., Spreeuwenberg, P.M.M., Dulmen, S. van, Bensing, J.M. Effects of communication skills training and a Question Prompt Sheet to improve communication with older cancer 7 patients: a randomized controlled trial. Critical Reviews in Oncology Hematology: 2011, 80(1), 145-159

Mirjam van Dijk, Judith de Groot, Nienke van der Meulen, Janneke Noordman, Jessika Ouwerkerk, Elise Posma, Marit Schotten and Frank Tol for their help in data gathering, development of the intervention and coding of the videotaped consultations. We gratefully acknowledge the Dutch Cancer Society (grant number NIVEL 2003-2973) for funding this study.

\section{REFERENCES}

[1] L. Fallowfield and V. Jenkins, Current concepts of communication skills training in oncology, Recent Results Cancer Res 168 (2006), pp. 105-112

[2] T.F. Hack, L.F. Degner and P.A. Parker, The communication goals and needs of cancer patients: a review, Psycho-Oncology 14 (2005), pp. 831-845.

[3] J. Jansen, J. van Weert, S. van Dulmen, T. Heeren and J. Bensing, Patient education about treatment in cancer care: an overview of the literature on older patients' needs, Cancer Nurs 30 (4) (2007), pp. 251260.

[4] T.A. Salthouse, The processing speed theory of adult age differences in cognition, Psychol Rev 103 (1996), pp. 403-428.

[5] L.C. McGuire, Remembering what the doctor said: organization and adults' memory for medical information, Exp Aging Res 22 (1996), pp. 403-428.

[6] R. Zacks and L. Hasher, Cognitive gerontology and attentional inhibition: a reply to Burke and McDowd, J Gerontol B 52 (1997), pp. 274-283.

[7] S.A. Valentijn, M.P. van Boxtel and S.A. van Hooren et al., Change in sensory functioning predicts change in cognitive functioning: results from a 6-year follow-up in the Maastricht Aging Study, J Am Geriatr Soc 53 (2005), pp. 374-380.

[8] J. Jansen, Communicating with older cancer patients: impact on information recall, NIVEL, Utrecht (2009).

[9] F. Craik and R. Lockhart, Levels of processing: a framework for memory research, J Verb Learn Verb Beh 11 (1972), pp. 671-684.

[10] P.G. Devine and E.R. Hirt, Message strategies for information campaigns: a social-psychological analysis. In: C.T. Salmon, Editor, Information campaigns: balancing social values and social change, Sage, Newbury Park, CA (1989), pp. 229-258.

[11] R.E. Ingram, Information processing and feedback: effects of mood and information favourability on the cognitive processing of personally relevant information, Cognit Ther Res 8 (4) (1984), pp. 371-386.

[12] R.E. Petty and J.T. Cacioppo, Attitudes and persuasion: classic and contemporary approaches, William C Brown, Dubuque, IA (1981).

[13] R.E. Petty and J.T. Cacioppo, The elaboration likelihood model of persuasion. In: L. Berkowitz, Editor, Advances in experimental social psychology, Academic Press, New York (1986), pp. 123-205.

[14] R.E. Petty, R. Goldman and J.T. Cacioppo, Personal involvement as a determinant of argument-based persuasion, J Pers Soc Psychol 41 (5) (1981), pp. 847-855.

[15] B.K. Rimer and M.W. Kreuter, Advancing tailored health communication: a persuasion and message effects perspective, J Commun 56 (2006), pp. S184-S201.

[16] M. De Vries, J.C.M. Van Weert, J. Jansen, V. Lemmens and H. Maas, Step by step development of a clinical pathway for older cancer patients, Eur J Cancer 43 (2007), pp. 2170-2178.

[17] T.M. Hess, Memory and aging in context, Psychol Bull 131 (2005), pp. 383-406.

[18] S.C. Brown and D.C. Park, Theoretical models of cognitive aging and implications for translational research in medicine, Gerontologist 43 (Spec no. 1) (2003), pp. 57-67.

[19] M.G. Greene and R.D. Adelman, Physician-older patient communication about cancer, Patient Educ Couns 50 (2003), pp. 55-60.

[20] P. Maguire, Improving communication with cancer patients, Eur J Cancer 35 (1999), pp. 2058-2065.

[21] Medical Research Council, A framework for the development and evaluation of RCTs for complex interventions to improve health, MRC, London (2000).

[22] P. Craig, P. Dieppe, S. Macintyre, S. Michie, I. Nazareth and M. Petticrew, Developing and evaluating complex interventions: the new Medical Research Council guidance, BMJ 337 (2008), p. a1655.

[23] E. Posma, J. Weert, J. van Jansen and J. Bensing, Older cancer patients' information and support needs surrounding treatment: an evaluation through the eyes of patients, relatives and professionals, BMC Nurs 8 (2009), p. 1.

[24] J. Jansen, J.C.M. Van Weert, N. Van der Meulen, S. Van Dulmen, T. Heeren and J. Bensing, Recall in older cancer patients: measuring memory for medical information, Gerontologist 48 (2) (2008), pp. 149157. 
Weert, J.C.M. van, Jansen, J., Spreeuwenberg, P.M.M., Dulmen, S. van, Bensing, J.M. Effects of communication skills training and a Question Prompt Sheet to improve communication with older cancer 7 patients: a randomized controlled trial. Critical Reviews in Oncology Hematology: 2011, 80(1), 145-159

[25] J.C.M. Van Weert, J. Jansen and A. De Best et al., In gesprek over chemotherapie deel 2. Een videoobservatie onderzoek naar patiëntgerichtheid en recall van informatie tijdens verpleegkundige voorlichting aan ouderen met kanker, Discussing chemotherapy part 2. A video-observation study on patientcenteredness and recall of information during patient education sessions to older cancer patients, NIVEL, Utrecht (2008).

[26] J.C.M. Van Weert, J. Jansen, G.J. de Bruijn, J. Noordman, A.M. Van Dulmen and J.M. Bensing, QUOTEchemo: a patient-centered instrument to measure quality of care through the patient's eyes preceding chemotherapy treatment, Eur J Cancer 45 (17) (2009), pp. 2967-2976.

[27] J. Jansen, J.C.M. Van Weert, L. Wijngaards-de Meij, S. Van Dulmen, T.J. Heeren and J. Bensing, Patient and companion recall of medical information, Psycho-Oncology 19 (2) (2010), pp. 170-179.

[28] J.C.M. Van Weert, J. Jansen and A. De Best et al., In gesprek over chemotherapie deel 1. Handvatten voor patiëntgerichte voorlichting aan ouderen met kanker, Discussing chemotherapy part 1. Handles for patient-centered patient education to older cancer patients, NIVEL, Utrecht (2008).

[29] R.S. Lazarus and S. Folkman, Stress, appraisal, and coping, Springer Press, New York (1984).

[30] R.S. Lazarus and S. Folkman, Relationship between coping and emotion: implications for theory and research, Soc Sci Med 26 (1988), pp. 309-325.

[31] J.E. Johnson, Self-regulation theory and coping with physical illness, Res Nurs Health 22 (1999), pp. 435-448.

[32] H. Leventhal, D.R. Nerenz and D.J. Steele, Illness representation and coping with health threats. In: A. Baum, S.E. Taylor and J.E. Singer, Editors, Handbook of psychology and health, Lawrence Erlbaum Associates, Hillsdale, NJ (1984), pp. 219-252.

[33] S.M. Miller, Monitoring and blunting of threatening information: cognitive interference: facilitation in the coping process. In: I. Sarason, B. Sarason and G.R. Pierce, Editors, Cognitive interference: theories, models, and findings, Lawrence Erlbaum, Hillside (1996), pp. 175-190.

[34] R.F. Brown, P.N. Butow, S.M. Dunn and M.H. Tattersall, Promoting patient participation and shortening cancer consultations: a randomised trial, Br J Cancer 85 (9) (2001), pp. 1273-1279.

[35] H. Schuurmans, N. Steverink, S. Lindenberg, N. Frieswijk and J.P.J. Slaets, Old or frail: what tells us more?, J Gerontol 59A (9) (2004), pp. 962-965.

[36] N. Steverink, J.P.J. Slaets, H. Schuurmans and M. Van Lis, Measuring frailty: developing and testing the GFI (Groningen Frailty Indicator), Gerontologist 41 (Special Issue 1) (2001), p. 236.

[37] H.M. Van der Ploeg, P.B. Defares and C.D. Spielberger, Handleiding bij de Zelfbeoordelings Vragenlijst (ZBV), Manual of the Dutch version of the State Trait Anxiety Inventory, Swets and Zeitlinger, Lisse (1980).

[38] M.A. Stanley, D.M. Novy, S.L. Bourland, J.G. Beck and P.M. Averill, Assessing older adults with generalized anxiety: a replication and extension, Behav Res Ther 39 (2) (2001), pp. 221-235.

[39] , State-Trait Anxiety Inventory (Selfevaluation Questionnaire) [program], Consulting Psychologists Press, Palo Alto University, California (1983).

[40] A. Pieterse, S. Van Dulmen, M. Ausems, A. Schoemaker, F. Beemer and J. Bensing, QUOTEGENEca: development of a counselee-centered instrument to measure needs and preferences in genetic counselling for hereditary cancer, Psycho-Oncology 14 (2005), pp. 361-375.

[41] H.J. Sixma, C. Van Campen, J.J. Kerssens and L. Peters, Quality of Care from the patients' perspectives: from theoretical concept to a new measuring instrument, Health Expect 1 (1998), pp. 82-95.

[42] J.H. Stubbe, T. Gelsema and D.M.J. Delnoij, The consumer quality index hip knee questionnaire measuring patients' experiences with quality of care after a total hip of knee arthroplasty, BMC Health Serv Res 7 (2007), p. 60.

[43] L.J.F. Rutten, N.K. Arora, A.D. Bakos, N. Aziz and J. Rowland, Information needs and sources of information among cancer patients: a systematic review of research (1980-2003), Patient Educ Couns 57 (3) (2005), pp. 250-261.)

[44] D.G. Altman, Practical statistics for medical research, Chapman \& Hall, London (1991).

[45] J. Rasbash, W. Browne, M. Healy, B. Cameron and C. Charlton, MlwiN (version 1.10), Multilevel models Project Institute of Education, London (2000).

[46] A.S. Bryk and S.W. Raudenbusch, Hierarchical linear models: applications and data management methods, Sage Publications, Newbury Park (1992).

[47] H. Goldstein, Multilevel statistical models, Halsted Press, New York (1995).

[48] S.C. Brown and D.C. Park, Roles of age and familiarity in learning health information, Educ Gerontol 28 (2002), pp. 695-710.

[49] J. Jansen, P. Butow and J.C.M. Van Weert et al., Does age really matter? Selective recall of information presented to newly referred cancer patients, J Clin Oncol 26 (2008), pp. 5450-5457.

[50] R.P.C. Kessels, Patients' memory for medical information, J Royal Soc Med 96 (2003), pp. $219-222$. 
Weert, J.C.M. van, Jansen, J., Spreeuwenberg, P.M.M., Dulmen, S. van, Bensing, J.M. Effects of communication skills training and a Question Prompt Sheet to improve communication with older cancer 7 patients: a randomized controlled trial. Critical Reviews in Oncology Hematology: 2011, 80(1), 145-159

[51] N. Leigh, M. Gattellari, P. Butow, R. Brown and M.H.N. Tattersall, Discussing adjuvant cancer therapy, J Clin Oncol 19 (6) (2001), pp. 1768-1778.

[52] I.N. Olver, S.J. Turrell, N.A. Olszeweski and K.J. Willson, Impact of an information and consent form on patients having chemotherapy, Med J Aust 162 (1995), pp. 82-83.

[53] D.G. Morrow, M. Weiner, J. Young, D. Steinley, M. Deer and M.D. Murray, Improving medication knowledge among older adults with heart failure: a patient-centered approach to instruction design, Gerontologist 45 (4) (2005), pp. 545-552.

[54] A.J. Mitchell, Reluctance to disclose difficult diagnoses: a narrative review comparing communication by psychiatrists and oncologists, Support Cancer Care 5 (2007), pp. 819-828.

[55] P. Schofield, M. Carey, A. Love, C. Nehill and S. Wein, Would you like to talk about your future treatment options? Discussing the transition from curative cancer treatment to palliative care, Palliat Med 20 (2006), pp. 397-406.

[56] J.M. Clayton, K.M. Hancock, P.N. Butow, M.H.N. Tattersall and D.C. Currow, Clinical practice guidelines for communicating prognosis and end-of-life issues with adults in the advanced stages of a lifelimiting illness, and their caregivers, Med J Aust 186 (12 Suppl.) (2007), pp. S77-S108.

[57] S.A. Christianson, Emotional stress and eyewitness memory: a critical review, Psychol Bull 112 (2) (1992), pp. 284-309.

[58] M.J. Pickersgill and A. Owen, Mood-States, recall and subjective comprehensibility of medical information in nonpatient volunteers, Pers Individual Differences 13 (12) (1992), pp. 1299-1305.

[59] Y. Hanoch and O. Vitouch, When less is more: information, emotional arousal and the ecological reframing of the Yerkes-Dodson law, Theory Psychol 14 (4) (2004), pp. 427-452.

[60] I. Wessel, P. van der Kooy and H. Merckelbach, Differential recall of central and peripheral details of emotional slides is not a stable phenomenon, Memory 8 (2) (2000), pp. 95-109.

[61] J.A. Easterbrook, The effect of emotion on cue utilization and the organization of behavior, Psychol Rev 66 (1959), pp. 183-201.

[62] J. Jansen, J.C.M. Van Weert, J. De Groot, S. Van Dulmen, T.J. Heeren and M. Bensing, Emotional and informational patient cues: the impact of nurses' responses on recall, Patient Educ Couns 79 (2) (2010), pp. 218-224.

[63] P. Ley, Understanding, memory, satisfaction and compliance, Br J Clin Psychol 21 (1982), pp. 241254.

[64] G.A. Miller, The magical number seven, plus or minus two: some limits on our capacity for processing information, Psychol Rev 63 (1956), pp. 81-89.

\section{VITAE}

Julia van Weert, Ph.D. is assistant professor health communication at the Amsterdam School of Communication Research (ASCoR) of the University of Amsterdam, The Netherlands. She is specialized in communication with older (cancer) patients and is (co-)author of many articles in this field. She was the recipient of the Public Health Award 2004 of the Association of Public Health and Science (2005), the prof. Dr. Schreuder Award of the Netherlands Association of Gerontology (2005) and a Cancer Research Award from the Dutch Cancer Society for research on communication with older cancer patients (2010). The NIVEL project (VOICE), described in this article, recently won the Medical Contact Communication Award 2009 (public price and 3rd jury price). 
Weert, J.C.M. van, Jansen, J., Spreeuwenberg, P.M.M., Dulmen, S. van, Bensing, J.M. Effects of communication skills training and a Question Prompt Sheet to improve communication with older cancer 7 patients: a randomized controlled trial. Critical Reviews in Oncology Hematology: 2011, 80(1), 145-159 ive

\section{TABLES AND FIGURES}

Fig. 1. Design of the study.

\begin{tabular}{|c|c|}
\hline \multicolumn{2}{|c|}{ MRC: Feasibility and piloting / Development (February 2005 - September 2006) } \\
\hline $\begin{array}{l}\text { Focus groups \& interviews patients \& relatives ( } \\
\text { Focus groups professionals (Posma et al., 2009) } \\
\text { Literature review (Jansen et al., 2007) [3] } \\
\text { Development recall measurement instrument (Ja1 } \\
\text { Development needs measurement instrument QU }\end{array}$ & $\begin{array}{l}\text { na et al., 2009) [23] } \\
\text { et al., 2008a) [24] } \\
E^{\text {chemo }} \text { (Van Weert et al., 2009) [26] }\end{array}$ \\
\hline $\begin{array}{l}\text { Experimental group } \\
6 \text { outpatient departments involved in nursing } \\
\text { education about chemotherapy treatment }\end{array}$ & $\begin{array}{l}\text { Control group } \\
6 \text { outpatient departments involved in } \\
\text { nursing education about chemotherapy } \\
\text { treatment }\end{array}$ \\
\hline $\begin{array}{l}\text { Pre-test } \\
64 \text { older cancer patients (aged } 65 \text { years or older) }\end{array}$ & $\begin{array}{l}\text { Pre-test } \\
51 \text { older cancer patients (aged } 65 \text { years } \\
\text { or older) }\end{array}$ \\
\hline
\end{tabular}

MRC: Development

Development intervention

(Van Weert et al., 2008a; 2008b) [25, 28]

MRC: Implementation (September 2006-April 2007; three months per ward)

\begin{tabular}{|c|c|c|}
\hline \multicolumn{2}{|c|}{ Intervention Experimental Group } & Intervention Control Group \\
\hline \multicolumn{3}{|c|}{ Intervention for Nurses } \\
\hline Week 1-3 & $\begin{array}{l}\text { Web-enabled video feedback \& } \\
\text { reflection task }\end{array}$ & Education as usual \\
\hline Week 3 & Communication skills training & \\
\hline Week 3-9 & $\begin{array}{l}\text { Practice, reflection task \& feedback } \\
\text { colleague }\end{array}$ & \\
\hline Week 9 & Follow-up meeting & \\
\hline Week 9-12 & Practice & \\
\hline \multicolumn{3}{|c|}{ Intervention for Patients } \\
\hline \multicolumn{3}{|c|}{ Booklet with QPS } \\
\hline
\end{tabular}

MRC: Evaluation (January 2007 - June 2008)

Post-test

55 older cancer patients (aged 65 years or older)

Post-test

40 older cancer patients (aged 65 years or older)

$\mathrm{MRC}=$ Key elements of the development and evaluation process according to the Medical Research Council guidance $[21,22]$. Note that, although it is useful to think in phases, in practice these may not follow a linear or cyclical sequence [22]. 
Weert, J.C.M. van, Jansen, J., Spreeuwenberg, P.M.M., Dulmen, S. van, Bensing, J.M. Effects of communication skills training and a Question Prompt Sheet to improve communication with older cancer 7 patients: a randomized controlled trial. Critical Reviews in Oncology Hematology: 2011, 80(1), 145-159

Fig. 2. New structure of the consultation.

\section{Part 1 \\ Introduction \\ Information about chemotherapy and side effects}

Break in which patients and significant others can reflect on the information given

\begin{tabular}{l}
\hline Part 2 \\
Other information and issues brought up by patients during break \\
Summary and conclusions
\end{tabular}

Table 1

Categories of the QUOTE ${ }^{\text {chemo }}$ and internal consistency of video-observation categories.

\begin{tabular}{|c|c|c|c|}
\hline Category & $\begin{array}{l}\text { Number } \\
\text { of items }\end{array}$ & Content & $\begin{array}{l}\text { Cronbach's } \alpha \text { QUOTE }^{\text {chemo }} \\
\text { Performance } \\
\text { (video-observations) }\end{array}$ \\
\hline \multicolumn{4}{|l|}{ Cancer-specific issues } \\
\hline Treatment-related information & 20 & $\begin{array}{l}\text { Purpose of treatment; how treatment works; treatment plan, description, } \\
\text { logistic information, tests and procedures, hospital routines; side effects } \\
\text { and physical effects of treatment; influence of treatment on sexuality; } \\
\text { preventing, reducing and reporting side effects, where to get information } \\
\text { about treatment }\end{array}$ & 0.92 \\
\hline Realistic expectations & 3 & $\begin{array}{l}\text { Life span or survival rate; effect on life plan or long term goals in the } \\
\text { future; outcome if no treatment }\end{array}$ & 0.72 \\
\hline Rehabilitation information & 11 & $\begin{array}{l}\text { Self care issues during treatment and recovery; dealing with side effects at } \\
\text { home; nutrition, effects on social life, leisure, employment or work life, } \\
\text { health behaviour and promotion }\end{array}$ & 0.87 \\
\hline \multicolumn{4}{|l|}{ Generic issues } \\
\hline Coping information & 7 & $\begin{array}{l}\text { Coping with cancer and treatment; community counseling or support; } \\
\text { support from other patients }\end{array}$ & 0.82 \\
\hline Interpersonal communication & 6 & $\begin{array}{l}\text { Effect of treatment on significant others, i.e. family members or friends; } \\
\text { attention to significant others }\end{array}$ & 0.72 \\
\hline Tailored communication & 10 & $\begin{array}{l}\text { Communication skills; knowledge of and adaptation to the patients } \\
\text { personal situation and preferences }\end{array}$ & 0.71 \\
\hline Affective communication & 10 & Empathizing, giving attention and emotional support, listening & 0.88 \\
\hline
\end{tabular}


Weert, J.C.M. van, Jansen, J., Spreeuwenberg, P.M.M., Dulmen, S. van, Bensing, J.M. Effects of communication skills training and a Question Prompt Sheet to improve communication with older cancer patients: a randomized controlled trial. Critical Reviews in Oncology Hematology: 2011, 80(1), 145-159

Table 2

Characteristics of participating patients by treatment group $(N=210)$

\begin{tabular}{|c|c|c|c|c|c|c|c|c|}
\hline & \multicolumn{4}{|c|}{ Pre-test } & \multicolumn{4}{|c|}{ Post-test } \\
\hline & \multicolumn{2}{|c|}{ Experimental $(n=64)$} & \multicolumn{2}{|c|}{ Control $(n=51)$} & \multicolumn{2}{|c|}{ Experimental $(n=55)$} & \multicolumn{2}{|c|}{ Control $(n=40)$} \\
\hline & $n^{\mathrm{a}}$ & $\%$ & $n^{\mathrm{a}}$ & $\%$ & $n^{\mathrm{a}}$ & $\%$ & $n^{\mathrm{a}}$ & $\%$ \\
\hline \multicolumn{9}{|l|}{ Gender } \\
\hline Male & 42 & 65.6 & 36 & 70.6 & 31 & 56.4 & 28 & 70.0 \\
\hline Female & 22 & 34.4 & 15 & 29.4 & 24 & 43.6 & 12 & 30.0 \\
\hline \multicolumn{9}{|l|}{ Age } \\
\hline$M(\mathrm{SD})$ & \multirow{2}{*}{\multicolumn{2}{|c|}{$\begin{array}{l}73.1(5.1)^{\mathrm{b}, * *} \\
(65.3-85.7)\end{array}$}} & \multirow{2}{*}{\multicolumn{2}{|c|}{$\begin{array}{l}71.1(3.6)^{\mathrm{b}, * *} \\
(65.6-79.2)\end{array}$}} & \multirow{2}{*}{\multicolumn{2}{|c|}{$\begin{array}{l}72.4(5.7) \\
(65.4-87.0)\end{array}$}} & \multirow{2}{*}{\multicolumn{2}{|c|}{$\begin{array}{l}71.8(4.2) \\
(65.0-79.8)\end{array}$}} \\
\hline Range & & & & & & & & \\
\hline \multicolumn{9}{|l|}{ Educational level } \\
\hline Low & 33 & 54.1 & 23 & 45.1 & 27 & 52.9 & 16 & 45.7 \\
\hline Middle & 9 & 14.8 & 9 & 17.6 & 10 & 19.6 & 9 & 25.7 \\
\hline High & 19 & 31.1 & 19 & 37.3 & 14 & 27.5 & 10 & 28.6 \\
\hline \multicolumn{9}{|l|}{ Living arrangements } \\
\hline Alone & 17 & 27.9 & 11 & 21.6 & 14 & 27.5 & 5 & 14.3 \\
\hline With partner & 38 & 62.3 & 37 & 72.5 & 34 & 66.7 & 28 & 80.0 \\
\hline With partner and child(ren) & 2 & 3.3 & 3 & 5.9 & 2 & 3.9 & 1 & 2.9 \\
\hline With child(ren) & 2 & 3.3 & 0 & 0 & 1 & 2.0 & 1 & 2.9 \\
\hline Other & 2 & 3.3 & 0 & 0 & 0 & 0 & 0 & 0 \\
\hline \multicolumn{9}{|l|}{ Primary tumor site } \\
\hline Breast & 6 & 9.4 & 4 & 7.8 & 4 & 7.3 & 2 & 5.3 \\
\hline Digestive-gastrointestinal & 29 & 45.3 & 16 & 31.4 & 23 & 41.8 & 15 & 39.5 \\
\hline Haematologic & 6 & 9.4 & 8 & 15.7 & 9 & 16.4 & 1 & 2.6 \\
\hline Lung & 11 & 17.2 & 17 & 33.3 & 8 & 14.5 & 14 & 36.8 \\
\hline Gynaecological & 1 & 1.6 & 3 & 5.9 & 2 & 3.6 & 2 & 5.3 \\
\hline Genitourinar & 10 & 15.6 & 3 & 5.9 & 6 & 10.9 & 3 & 7.9 \\
\hline Other & 1 & 1.6 & 0 & 0 & 3 & 5.5 & 1 & 2.6 \\
\hline \multicolumn{9}{|l|}{ Time since diagnosis (months) } \\
\hline$M(\mathrm{SD})$ & \multicolumn{2}{|c|}{$5.4(12.9)$} & \multicolumn{2}{|c|}{$2.0(4.4)$} & \multicolumn{2}{|c|}{$3.1(6.0)$} & \multicolumn{2}{|c|}{$3.5(10.5)$} \\
\hline Median & \multicolumn{2}{|c|}{1.4} & \multicolumn{2}{|c|}{1.2} & \multicolumn{2}{|c|}{1.3} & \multicolumn{2}{|c|}{1.4} \\
\hline \multicolumn{9}{|l|}{ Treatment intent } \\
\hline Curative & 15 & 28.8 & 15 & 38.5 & 19 & 37.3 & 9 & 25.0 \\
\hline Palliative & 37 & 71.2 & 24 & 61.5 & 32 & 62.7 & 27 & 75.0 \\
\hline \multicolumn{9}{|l|}{ Frailty $(\mathrm{GFI} ; 0-15)^{\mathrm{c}}$} \\
\hline$M(\mathrm{SD})$ & 2.6 & & 2.2 & & 2.3 & & 2.4 & \\
\hline Anxiety $(\mathrm{STAI} ; 10-40)^{\mathrm{c}}$ & & & & & & & & \\
\hline$M(S D)$ & 21. & & 21.8 & & 19. & & 20. & \\
\hline
\end{tabular}

${ }^{a} n$ varies slightly due to missing data.

b Significant difference between experimental group in pre-test and control group in pre-test.

c Scores in italics indicate the most favourable score (least frailty/anxiety) for the scale.

** $p<.01$.

Table 3

Characteristics of participating nurses at baseline by treatment group $(N=48)$.

\begin{tabular}{|c|c|c|c|c|}
\hline & \multicolumn{2}{|c|}{ Experimental group $(n=32)$} & \multicolumn{2}{|c|}{ Control group $(n=26)$} \\
\hline & $\mathrm{n}^{\mathrm{a}}$ & $\%$ & $\mathrm{n}^{\mathrm{a}}$ & $\%$ \\
\hline \multicolumn{5}{|l|}{ Gender } \\
\hline Female & 29 & 90.6 & 26 & 100 \\
\hline Male & 3 & 9.4 & 0 & 0 \\
\hline \multicolumn{5}{|l|}{ Age } \\
\hline$M(\mathrm{SD})$ & \multicolumn{2}{|c|}{$41.4(9.2)$} & \multicolumn{2}{|c|}{$41.1(6.8)$} \\
\hline \multicolumn{5}{|l|}{ Experience as a nurse (years) } \\
\hline$M(\mathrm{SD})$ & \multicolumn{2}{|c|}{$16.6(8.4)$} & \multicolumn{2}{|c|}{$18.2(7.9)$} \\
\hline \multicolumn{5}{|l|}{ Experience in oncology } \\
\hline$M(\mathrm{SD})$ & \multicolumn{2}{|c|}{$10.9(7.4)$} & \multicolumn{2}{|c|}{$14.1(7.3)$} \\
\hline \multicolumn{5}{|l|}{ Employed on this ward (years) } \\
\hline$M(\mathrm{SD})$ & \multicolumn{2}{|c|}{$11.1(8.0)$} & \multicolumn{2}{|c|}{$9.4(7.1)$} \\
\hline \multicolumn{5}{|l|}{ Position } \\
\hline (Oncology) nurse & 26 & 81.3 & 19 & 73.1 \\
\hline Specialized oncology nurse & 6 & 18.8 & 7 & 26.9 \\
\hline
\end{tabular}

No significant differences between experimental nurses and control nurses at baseline.

a $n$ varies slightly due to missing data. 
Weert, J.C.M. van, Jansen, J., Spreeuwenberg, P.M.M., Dulmen, S. van, Bensing, J.M. Effects of communication skills training and a Question Prompt Sheet to improve communication with older cancer patients: a randomized controlled trial. Critical Reviews in Oncology Hematology: 2011, 80(1), 145-159

Table 4

Effects of the intervention on consult duration and communication skills $(N=210)$

\begin{tabular}{|c|c|c|c|c|c|c|c|c|c|c|c|c|}
\hline \multirow[t]{3}{*}{ Outcome measures } & \multicolumn{4}{|c|}{ Pre-test } & \multicolumn{4}{|c|}{ Post-test } & \multirow{3}{*}{$\begin{array}{l}\text { Pre-/post } \\
\text { Change } E\end{array}$} & \multirow{3}{*}{$\begin{array}{l}\text { Pre-/post } \\
\text { Change } C\end{array}$} & \multirow{3}{*}{$\begin{array}{l}\text { Total change } \\
\text { score }^{\mathrm{a}}\end{array}$} & \multirow[t]{3}{*}{$\chi^{2}(1)$} \\
\hline & \multicolumn{2}{|c|}{$\begin{array}{l}\text { Experimental } \\
(n=64)\end{array}$} & \multicolumn{2}{|c|}{ Control $(n=51)$} & \multicolumn{2}{|c|}{$\begin{array}{l}\text { Experimental } \\
(n=55)\end{array}$} & \multicolumn{2}{|c|}{ Control $(n=40)$} & & & & \\
\hline & $M$ & se & $M$ & se & $M$ & se & $M$ & se & & & & \\
\hline \multicolumn{13}{|l|}{ Consultation duration } \\
\hline Duration (min) & 55.72 & 2.61 & 54.74 & 2.90 & 56.83 & 2.84 & 57.37 & 3.52 & 1.11 & 2.63 & 1.55 & 0.07 \\
\hline \multicolumn{13}{|l|}{ Cancer-specific issues (scale 1-4) } \\
\hline Treatment-related information & 2.93 & 0.10 & 2.69 & 0.10 & 2.78 & 0.10 & 2.74 & 0.10 & -0.15 & 0.05 & -0.20 & 2.07 \\
\hline Realistic expectations & 1.15 & 0.09 & 1.40 & 0.09 & 1.60 & 0.12 & 1.19 & 0.14 & $0.45^{* *}$ & -0.20 & $0.65^{* *}$ & 8.48 \\
\hline Rehabilitation information & 2.35 & 0.08 & 2.23 & 0.09 & 1.99 & 0.09 & 2.31 & 0.10 & $-0.38^{* * *}$ & 0.08 & $-0.45^{* *}$ & 7.17 \\
\hline \multicolumn{13}{|l|}{ Generic issues (scale 1-4) } \\
\hline Coping information & 1.70 & 0.12 & 1.65 & 0.12 & 1.92 & 0.12 & 1.73 & 0.12 & 0.22 & 0.09 & 0.13 & 0.69 \\
\hline Interpersonal communication & 2.08 & 0.11 & 1.96 & 0.12 & 2.45 & 0.09 & 2.10 & 0.10 & $0.37^{* *}$ & 0.13 & $0.24^{\mathrm{b}}$ & 1.57 \\
\hline Tailored communication & 1.95 & 0.06 & 1.80 & 0.06 & 2.24 & 0.07 & 1.97 & 0.08 & $0.29^{* *}$ & 0.16 & $0.13^{\mathrm{c}}$ & 0.90 \\
\hline Affective communication & 3.08 & 0.12 & 3.05 & 0.12 & 3.43 & 0.11 & 3.10 & 0.11 & $0.35^{* *}$ & 0.05 & $0.30^{\mathrm{d}}$ & 2.37 \\
\hline
\end{tabular}

${ }^{* * *} p<.01$.

**** $p<.001$

a Scores in italics indicate that the pre-/post-change in the experimental group is significantly different from the pre-/post-change in the control group (analysis adjusted for patients' age, gender and education). E, experimental group; C, control group; se, standard error; $\chi^{2}(1)=$ Chi-square $(1$ degree of freedom).

b $\chi^{2}(2)=$ Chi square $(2$ degree of freedom $)=9.63(p<.01)$, indicating that the experimental group improved, but this is masked because the control group improved also.

c $\chi^{2}(2)=$ Chi square $(2$ degree of freedom $)=13.04(p<.001)$

d $\chi^{2}(2)=$ Chi square $(2$ degree of freedom $)=7.29(p<.05)$.

Table 5

Effects of the intervention on provision of information and recommendations (mean number of items discussed) $(n=161)$.

\begin{tabular}{|c|c|c|c|c|c|c|c|c|c|c|c|c|}
\hline \multirow[t]{2}{*}{ Outcome measures } & \multicolumn{4}{|l|}{ Pre-test } & \multicolumn{4}{|l|}{$\underline{\text { Post-test }}$} & \multirow{2}{*}{$\begin{array}{l}\text { Pre-/post } \\
\text { change } E\end{array}$} & \multirow{2}{*}{$\begin{array}{l}\text { Pre-/post } \\
\text { change } C\end{array}$} & \multirow{2}{*}{$\begin{array}{l}\text { Total } \\
\text { change } \\
\text { score }^{\mathrm{a}}\end{array}$} & \multirow[t]{2}{*}{$\chi^{2}(1)$} \\
\hline & $\begin{array}{l}E \\
(n=48)\end{array}$ & se & $\begin{array}{l}C \\
(n=39)\end{array}$ & se & $\begin{array}{l}E \\
(n=48)\end{array}$ & se & $\begin{array}{l}C \\
(n=26)\end{array}$ & se & & & & \\
\hline Information total & 45.17 & 2.65 & 40.99 & 2.64 & 37.95 & 2.37 & 43.65 & 2.44 & $-7.22^{* * *}$ & 2.65 & $-9.87^{* * *}$ & 9.80 \\
\hline \multicolumn{13}{|l|}{ Introduction } \\
\hline History taking & 6.56 & 0.92 & 4.66 & 0.91 & 4.23 & 0.90 & 6.48 & 0.95 & $-2.33^{* *}$ & $1.83^{*}$ & $-4.17^{* * *}$ & 12.49 \\
\hline General information & 3.31 & 0.27 & 2.87 & 0.29 & 3.69 & 0.26 & 2.60 & 0.32 & 0.37 & -0.27 & 0.64 & 1.71 \\
\hline Cancer-specific information & 1.66 & 0.25 & 1.40 & 0.27 & 2.05 & 0.19 & 1.43 & 0.24 & 0.39 & 0.03 & 0.36 & 0.66 \\
\hline \multicolumn{13}{|l|}{ Treatment } \\
\hline Side effects & 21.02 & 1.66 & 20.29 & 1.62 & 15.31 & 1.62 & 22.27 & 1.66 & $-5.71^{* * *}$ & 1.98 & $-7.68^{* * *}$ & 16.92 \\
\hline Blood and bone marrow & 6.48 & 0.73 & 6.08 & 5.16 & 5.16 & 0.72 & 5.79 & 0.80 & $-1.58^{*}$ & -0.20 & -1.38 & 1.36 \\
\hline Digestive system & 4.82 & 0.33 & 4.96 & 3.68 & 3.68 & 0.32 & 4.94 & 0.36 & $-1.15^{* * *}$ & -0.02 & $-1.13^{*}$ & 6.46 \\
\hline Skin and hair & 4.31 & 0.54 & 4.01 & 3.02 & 3.02 & 0.56 & 5.05 & 0.58 & $-1.29^{* *}$ & $1.03^{*}$ & $-2.32^{* * *}$ & 13.98 \\
\hline Mouth & 1.93 & 0.21 & 1.81 & 1.04 & 1.04 & 0.21 & 1.86 & 0.27 & $-0.89^{* *}$ & 0.05 & $-0.93^{*}$ & 4.46 \\
\hline General well-being and fatigue & 1.39 & 0.18 & 1.32 & 1.16 & 1.16 & 0.21 & 2.07 & 0.23 & -0.23 & $0.75^{* *}$ & $-0.98^{* *}$ & 9.91 \\
\hline General information & 1.08 & 0.13 & 1.27 & 1.11 & 1.11 & 0.11 & 1.39 & 0.14 & 0.03 & 0.12 & -0.09 & 0.11 \\
\hline Eyes and ears & 0.47 & 0.12 & 0.63 & 0.15 & 0.15 & 0.10 & 0.85 & 0.13 & $-0.33^{*}$ & 0.23 & $-0.55^{*}$ & 5.03 \\
\hline Sexuality & 0.40 & 0.19 & 0.59 & 0.15 & 0.15 & 0.16 & 0.54 & 0.17 & -0.25 & -0.08 & -0.19 & 0.59 \\
\hline Details of therapy & 9.90 & 0.68 & 8.86 & 0.69 & 9.98 & 0.60 & 8.18 & 0.66 & 0.08 & 0.08 & 0.76 & 0.51 \\
\hline Hospital routines & 2.77 & 0.39 & 2.63 & 0.42 & 2.66 & 0.36 & 2.56 & 0.44 & -0.11 & -0.11 & -0.05 & 0.00 \\
\hline Recommendations total & 33.58 & 3.94 & 34.86 & 3.85 & 24.54 & 3.59 & 36.51 & 3.52 & $-9.04^{* * *}$ & 1.65 & $-10.68^{* *}$ & 9.55 \\
\hline \multicolumn{13}{|l|}{ Recommendations side effects } \\
\hline Digestive system & 7.23 & 1.08 & 7.78 & 1.01 & 5.18 & 0.93 & 7.40 & 0.98 & $-2.05^{*}$ & -0.38 & -1.67 & 1.27 \\
\hline Eating, drinking and nausea & 5.71 & 0.90 & 6.85 & 0.90 & 4.62 & 0.81 & 6.31 & 0.85 & -1.09 & -0.35 & -0.55 & 0.20 \\
\hline Stools & 1.55 & 0.30 & 0.99 & 0.31 & 0.61 & 0.21 & 1.17 & 0.25 & $-0.94^{* *}$ & 0.18 & $-1.12^{*}$ & 9.11 \\
\hline Hygiene & 5.21 & 0.71 & 6.00 & 0.72 & 4.11 & 0.76 & 6.24 & 0.87 & -1.10 & 0.24 & -1.34 & 1.52 \\
\hline Mouth & 5.28 & 0.74 & 4.05 & 0.74 & 2.49 & 0.67 & 3.98 & 0.68 & $-2.79^{* * *}$ & -0.07 & $-2.72^{* * *}$ & 12.81 \\
\hline Skin and hair & 3.49 & 0.58 & 3.32 & 0.59 & 2.35 & 0.49 & 4.72 & 0.53 & $-1.15^{\#}$ & $1.40^{*}$ & $-2.55^{* *}$ & 7.59 \\
\hline General well-being and Fatigue & 2.44 & 0.43 & 2.97 & 0.44 & 1.83 & 0.40 & 2.98 & 0.46 & -0.61 & 0.02 & -0.63 & 0.86 \\
\hline Blood and bone Marrow & 0.82 & 0.21 & 1.18 & 0.23 & 0.83 & 0.17 & 1.21 & 0.21 & 0.01 & 0.02 & -0.01 & 0.00 \\
\hline Sexuality & 0.46 & 0.21 & 0.61 & 0.20 & 0.16 & 0.20 & 0.58 & 0.20 & $-0.30^{*}$ & -0.03 & -0.28 & 1.41 \\
\hline Eyes and ears & 0.24 & 0.13 & 0.36 & 0.13 & 0.06 & 0.11 & 0.47 & 0.12 & -0.18 & 0.11 & -0.29 & 1.97 \\
\hline Side effects to report & 8.17 & 0.92 & 6.69 & 0.92 & 5.98 & 0.78 & 8.26 & 0.80 & $-2.19^{* *}$ & 1.57 & $-3.76^{* * *}$ & 11.93 \\
\hline
\end{tabular}

\# $p<.10$.

${ }^{*} p<.05$.

** $p<.01$.

** $p<.001$.

a Scores in italics indicate that the pre-/post-change in the experimental group is significantly different from the pre-/post-change in the control group (analysis adjusted for patients' age, gender and education). E, experimental group. C, control group. se, standard error. $\chi^{2}$ (1), Chi square (1 degree of freedom). 
Weert, J.C.M. van, Jansen, J., Spreeuwenberg, P.M.M., Dulmen, S. van, Bensing, J.M. Effects of communication skills training and a Question Prompt Sheet to improve communication with older cancer 7 patients: a randomized controlled trial. Critical Reviews in Oncology Hematology: 2011, 80(1), 145-159

Table 6

Effects of the intervention on recall of information $(n=161)$

\begin{tabular}{|c|c|c|c|c|c|c|c|c|c|c|c|c|}
\hline \multirow[t]{2}{*}{ Outcome measures } & \multicolumn{8}{|l|}{ Pre-test } & \multirow{2}{*}{$\begin{array}{l}\text { Pre-/post } \\
\text { change } E\end{array}$} & \multirow{2}{*}{$\begin{array}{l}\text { Pre-/post } \\
\text { change } C\end{array}$} & \multirow{2}{*}{$\begin{array}{l}\text { Total } \\
\text { change } \\
\text { score }^{\mathrm{a}}\end{array}$} & \multirow[t]{2}{*}{$\chi^{2}(1$} \\
\hline & $E(n=48)$ & se & $C(n=39)$ & se & $E(n=48)$ & se & $C(n=26)$ & se & & & & \\
\hline Recommendations Total (\% recall) & 18.31 & 2.46 & 25.17 & 2.60 & 24.70 & 2.87 & 21.83 & 3.57 & $6.39^{\#}$ & -3.34 & $9.73^{\#}$ & 3.18 \\
\hline \multicolumn{13}{|c|}{ Recommendations side effects (\% recall) } \\
\hline Digestive system & 15.35 & 3.35 & 18.62 & 3.51 & 22.73 & 3.62 & 22.02 & 4.56 & 7.39 & 3.40 & 3.99 & 0.26 \\
\hline Hygiene & 19.94 & 4.42 & 30.65 & 4.82 & 42.35 & 5.28 & 28.26 & 6.32 & $22.41 * *$ & -2.38 & $24.79 *$ & 5.58 \\
\hline Mouth & 32.84 & 5.08 & 20.05 & 5.38 & 38.69 & 5.76 & 32.39 & 6.43 & 5.85 & $12.34^{\#}$ & -6.49 & 0.43 \\
\hline Skin and hair & 35.31 & 6.34 & 44.78 & 5.82 & 24.86 & 5.06 & 23.70 & 5.82 & -10.45 & $-20.08 * *$ & 9.62 & 0.86 \\
\hline General well-being and fatigue & 30.07 & 6.46 & 32.18 & 6.85 & 28.43 & 5.24 & 10.92 & 6.11 & -1.64 & $-21.26 *$ & 19.62 & 2.53 \\
\hline Side effects to report (\% recall) & 11.48 & 3.61 & 26.58 & 3.79 & 20.65 & 4.26 & 19.88 & 5.19 & 9.17 & -6.70 & $15.86^{*}$ & 3.86 \\
\hline
\end{tabular}

Side effects to report (\% recal $)$

$\# p<.10, * p<.05, * * p<.01$

a Scores in italics indicate that the pre-/post-change in the experimental group is significantly different from the pre-/post-change in the control group (analysis adjusted for patients' age, gender and education). E, experimental group. C, control group. se, standard error. $\chi^{2}$ (1), Chi square (1 degree of freedom). 